\title{
Autarquia e escola: a gestão do pessoal não docente
}

Maria João de Carvalho mjcc@utad.pt

Universidade de Trás-os-Montes e Alto Douro, Portugal http://orcid.org/0000-0002-6870-849X

ArMando Felizardo
felizardoap@sapo.pt
Escola EB 2,3/S DE VILA Flor, PortugaL
http://orcid.org/0000-0002-1878-067X

\section{Resumo}

Em Portugal assistimos à mudança gradual do paradigma das políticas educativas, sendo que o poder local tem, progressivamente, adquirido novas competências no domínio da educação. Assim, procuramos conhecer o modo como se articulam a autarquia e a escola na gestão do Pessoal Não Docente.

Para o efeito realizamos um estudo de caso, com recurso à entrevista semiestruturada e à análise de conteúdo na interpretação e análise dos dados.

Foi possível concluir que a competência da gestão do Pessoal Não Docente é desvalorizada, e que a relação que se estabelece entre a escola e a autarquia nem sempre se revela articulada.

\section{Palavras-chave}

Pessoal não docente; contrato de execução; agrupamento de escolas: políticas educativas

\section{Resumen}

En Portugal asistimos al cambio gradual del paradigma de las políticas educativas, siendo que el poder local ha adquirido progresivamente nuevas competencias en el dominio de la educación. De esta forma, buscamos conocer el modo cómo se articulan la autarquía y la escuela en la gestión del personal no docente.

Para ello hemos realizado un estudio de caso, utilizando la entrevista semiestructurada y el análisis de contenido en la interpretación y análisis de los datos.

Fue posible concluir que la competencia de la gestión del personal no docente es desvalorizada, y que la relación que se establece entre la escuela y la autarquía no siempre se revela articulada.

\section{Palabras clave}

Personal no docente; contrato de trabajo; agrupación de escuelas; política educativa

\section{Abstract}

In Portugal we are witnessing the gradual change in the paradigm of the educational policies, since the local power has gradually gained new competences in the ruling of the education.

Therefore, we want to know the way how autarchy and school are articulated in the management by the non-teaching staff. To this end, we have conducted a case study based on semi-structured interviews, data analysis and content analysis for interpretation.

A conclusion was drawn that the competence of the non-teaching staff management is devalued and that the relationship between school and autarchy is not always an articulated one.

\section{Keywords}

Non-teaching staff; work contract; schools grouping; educational policy

Para citar este artigo / / To cite this article

De Carvalho, M. J. \& Felizardo, A. (2019). Autarquia e escola: a gestão do pessoal não docente. magis, Revista Internacional de Investigación en Educación, 11 (23), 115-134. doi: 10.11144/Javeriana.m11-23.aegp 


\section{Introdução}

Com o enfraquecimento do Estado Educador, assistimos à crescente valorização do local como forma de acolher e fomentar a participação dos atores locais nos processos educativos, num contexto de matriz democrática. Como afirmava António Sousa Fernandes (1996), no início deste processo, "O dinamismo local dos municípios, juntamente com as escolas e outros parceiros educativos está a conquistar progressivos espaços de autonomia deixados em aberto pelo imobilismo e rigidez da administração de ensino centralizada que ainda predomina" (p. 119).

É neste enquadramento que na década de 90 do século passado, fruto da situação política, surgem iniciativas legislativas favoráveis à descentralização, também denominada de municipalização ou territorialização das políticas educativas. Desde então, no domínio da educação, o município viu formalizadas e alargadas as suas competências, sendo-lhe reconhecido o papel de coordenadora local da política educativa. Assistimos, pois, ao "surgimento de um novo princípio de governança assente na territorialização de vários domínios, entre os quais a educação" (Seabra, Carmo, Baptista \& Fontes, 2012, p. 9).

\section{A territorialização das políticas educativas: as competências municipais}

Após o 25 de Abril de 1974, a Constituição da República Portuguesa, de 4 de Abril de 1976, ao mesmo tempo que consagra os princípios da participação democrática no ensino (art. ${ }^{\circ} 77^{\circ}$ ) e da descentralização administrativa (art. ${ }^{\circ} 27^{\circ}$ ), também integra as autarquias locais, nas quais se incluem as freguesias, os municípios e as regiões administrativas, na organização democrática do Estado.

Mais tarde, em 1986, a Lei de Bases do Sistema Educativo estabelece Descripción del artículo

Este artigo enquadra-se na investigação realizada no âmbito do mestrado de Ciências da Educação/Administração Educacional Autarquia e Escola: a questão da gestão do Pessoal Não Docente. Se num primeiro momento se incidiu sobre a valorização do local/municípios no domínio da educação, sendo que a pretexto da propagada descentralização o governo procura reconfigurar e recentrar o seu poder, alavancando-o nos municípios, agora instituidas como instâncias periféricas da Administração Central, em segundo lugar pretendeu-se conhecer o modo como se relacionam a escola e o município quando em causa está a gestão do Pessoal Não Docente.

diferentes níveis de administração, quando sinaliza as funções da administração central e institui que "A nível regional, e com o objetivo de integrar, coordenar e acompanhar a atividade educativa, será criado em cada região um departamento regional de educação" (art. ${ }^{\circ} 44^{\circ}$, n. $^{\circ} 2$ ).

A crescente valorização do poder local decorre da ação política e social de movimentos que, surgindo de forma espontânea, procuraram combater os atrasos e assimetrias das periferias face ao centro de poder/ administração e que o trabalho de António Francisco Baixinho (2011) e Donaldo Bello de Souza e Lia Ciomar Macedo de Faria (2004) tão bem expressa. A ação destes movimentos compreende-se e enquadra-se na generalizada e nova tendência de descentralização das administrações públicas (Pinhal, 2013).

No caso da Europa verificam-se diferentes grupos de desenvolvimento no processo de descentralização educativa. Portugal enquadra-se, à semelhança de França, no tipo de sistema centralizado com autonomia limitada das escolas, na medida em que cabe ao governo central a definição do planeamento e regras na generalidade das áreas, sendo, também, a principal fonte de financiamento.

A Grécia, Itália e Roménia caraterizam-se por serem sistemas predominantemente com autonomia limitada das escolas. Neste, o governo central, permanece predominante na definição e gestão do sistema, mas delega às escolas ou autoridades regionais e locais algumas responsabilidades de gestão de recursos. É ao nível da autonomia das escolas e na certificação ou controlo da qualidade, sendo que neste tipo de sistema as escolas são as responsáveis pelos exames com efeitos de certificação e as 
avaliações externas são raras, que residem as principais diferenças relativamente ao anterior.

Nos sistemas federais, com importância a nível das regiões, encontram-se países com Alemanha, Espanha e Bélgica. Nestes são as autoridades regionais que estão no centro do sistema educativo, definindo regras e gerindo, mas partilhando de forma diferenciada as responsabilidades com os níveis inferiores. É um tipo mais heterogéneo, a começar pelo grau de autonomia que é concedido às escolas, embora todos se caraterizem pelo caráter federal. A imposição de standars nacionais ou de cooperação entre regiões vieram introduzir elementos que apontam para a centralização dos sistemas.

A Dinamarca, Finlândia e Polónia enquadram-se nos sistemas de colaboração entre o estado e o poder local. Este tipo carateriza-se por uma regulação partilhada dos sistemas entre o governo central e as autoridades locais. De notar que as autoridades locais e as escolas são os níveis com maior peso de decisão na gestão de recursos financeiros e de pessoal.

Nos sistemas centralizados, com muita autonomia das escolas, encontramos a Inglaterra, a Suécia e a Holanda. Aqui as escolas e os poderes políticos locais, ou ambos, têm poderes e responsabilidade consideráveis, enquanto o governo central assegura funções de planeamento, definição de estruturas e controlo/ avaliação (Baptista, 2014).

Ao longo das últimas quatro décadas, em Portugal, este novo ímpeto descentralizador foi-se progressivamente materializando num quadro normativo que, apesar das muitas resistências, procurou legitimar e ampliar as atribuições e competências das autarquias locais. Por outro lado, mas não menos relevante, as autarquias foram assumindo competências diversas ao procurar, por sua própria iniciativa, intervir à margem do quadro legal (Fernandes, 2005, 2014; Pinhal, 2004, 2006, 2011, 2013).

Assim, o estudo das competências autárquicas no domínio educativo, nomeadamente no que concerne ao papel do município, implica valorizar simultaneamente:

a importância que o quadro legal assume como legitimador de caminhos a seguir por um número substancialmente mais alargado de agentes. E [...] o potencial criativo que assumem certas 'infidelidades normativas', o que [...] pode representar políticas educativas locais verdadeiramente autónomas (Neto-Mendes, 2007, p. 6).

Encontramos esta dicotomia em João Manuel da Silva Pinhal (2004, 2006, 2011, 2013) quando classifica as competências educacionais dos municípios em competências e não-competências, entendendo por estas últimas a intervenção dos municípios em áreas a que não estão obrigados por lei, ou seja, compreende todas as ações que transcendam as competências legais, procurando acudir aos problemas com que os munícipes se deparam. Estamos no domínio em que a ação política dos municípios, muitas vezes antecipando-se à lei, se desenvolve em áreas não previstas ou excedem os níveis de concretização determinados por lei. Na mesma linha de pensamento podemos situar António Sousa Fernandes (2005, 2014), quando distingue quatro tipos de atividades educativas dos municípios, que por conveniência podemos agrupar em tarefas/atividades educativas estabelecidas e autorizadas por lei e em atividades de iniciativa municipal e de intervenção e mediação políticas. Estas tipologias de competências e atividades assentam no critério da "prescrição legal".

Tais perspetivas implicam privilegiar a compreensão dialética da incontornável complementaridade que existe entre o formalismo das competências legais e o informalismo da iniciativa autónoma/extra-competência que os municípios assumem no setor da educação.

\section{Competências legais}

No período democrático o município deixou de desempenhar apenas funções meramente instrumentais e de complemento ao poder central. Com efeito, "Passou-se de uma situação de falta de autonomia face ao poder central para a assunção de projetos de desenvolvimento pensados e executados ao nível local por eleitos e organizações locais" (Pinhal, 2013, p. 131).

Na verdade, a Constituição da República Portuguesa, enquanto lei fundamental, quando considera as autarquias locais como "pessoas coletivas territoriais dotadas de órgãos representativos, que visam a prossecução dos interesses próprios das populações respectivas" (art. $235^{\circ}$, n. ${ }^{\circ} 2$ ), não deixa de reconhecer e legitimar a existência de interesses específicos das populações locais.

No entanto, só em 1984 através do Decreto-Lei n. ${ }^{\circ} 77 / 84$, de 8 de Março, e dando cumprimento à Lei n. ${ }^{\circ} 1 / 79$, de 2 de Janeiro, ocorre a regulamentação das competências autárquicas em matéria de investimentos públicos, nos quais se inclui a educação e ensino. Aí (art. ${ }^{\circ} 8^{\circ}$, al. e), na linha das reformas legislativas implementadas em períodos anteriores, são consignadas aos municípios responsabilidades nos domínios: construção de edifícios escolares; manutenção e equipamento das escolas do ensino primário e pré-escolar; residências e transportes escolares; ocupação dos tempos livres e ações de cariz social e equipamentos para educação de base de adultos.

Neste cenário, mais do que definir competências educativas, são atribuídos encargos financeiros aos municípios, pois, como salienta António Sousa 
Fernandes (1995), deste normativo transparece que o município não vê alterado o seu papel, mas "continua a ser considerado um mero comparticipante dos custos da educação, sem qualquer direito, mesmo limitado, de interferir na sua administração" (p. 55).

Também nesta fase, a Lei de Bases do Sistema Educativo é um marco incontornável para a compreensão das atribuições municipais no contexto educativo, desbravando o caminho para o reconhecimento e a valorização do município "como parceiro social na definição e gestão da política educativa nacional e local" (Fernandes, 2004, p. 37).

A partir dos meados da década de 90 , fruto do contexto político favorável à descentralização, a intervenção autárquica aprofunda-se e acentua-se traduzindo-se na denominada territorialização das políticas educativas. Nesse período a institucionalização legal da descentralização materializa-se na publicação da Lei n. ${ }^{\circ}$ 159/99, de 14 de Setembro, que estabelece o quadro de transferência de atribuições e competências para as autarquias locais. No que concerne à educação, o art. $^{0} 1^{\circ}{ }^{\circ}$, além das competências instrumentais já atribuídas, estabelece novas competências dos órgãos municipais: a elaboração da carta escolar a integrar nos planos diretores municipais, a criação dos conselhos locais de educação, já previstos no Decreto Lei n. ${ }^{\circ} 115-A / 98$, de 4 de Maio, e a gestão do Pessoal Não Docente de educação pré-escolar e do $1^{\circ}$ ciclo do Ensino Básico.

Com o Decreto Lei n. ${ }^{\circ}$ 7/2003, de 15 de Janeiro, regulamentam-se os Conselhos Municipais de Educação, antes designados Conselhos Locais de Educação, e as Cartas Educativas, inicialmente denominadas Cartas Escolares. Este normativo estabelece a obrigatoriedade da criação dos Conselhos Municipais de Educação e da elaboração das Cartas Educativas. Decisivamente, aos municípios é-lhes reconhecido um importante papel na conceção do sistema educativo local (Pinhal, 2004), dotados agora de instrumentos de coordenação das políticas educativas locais (Fernandes, 2014).

Em 2008 surge o Decreto Lei n. ${ }^{\circ}$ 144/2008, de 28 de Julho, que reconhecendo dificuldades na implementação do processo descentralizador consagra, no seu preâmbulo, a "transferência efectiva de competências para os órgãos dos municípios em matéria de educação, no que diz respeito à educação pré-escolar e ao ensino básico". Ao prever o estabelecimento de Contratos de Execução (CE) entre o Ministério da Educação e várias Câmaras Municipais contribuiu para o incremento do ritmo de transferência de competências da administração central para a local. Abriu-se espaço para a redistribuição das competências que até agora eram atribuídas às escolas/agrupamentos de escolas ${ }^{1}$ ou aos serviços da administração central. Assim, instrumentalizando a contratualização, prevê-se que competências significativas passem para a tutela dos municípios, como é o caso da contratação e gestão de carreiras do Pessoal Não Docente (PND) da educação pré-escolar e básica, da gestão da componente de apoio socioeducativo, da implementação das atividades de enriquecimento curricular, da gestão do parque escolar dos $2^{\circ}$ e $3^{\circ}$ ciclos e dos transportes escolares. O CE tem o mérito de poder aumentar e diversificar a oferta de formação ao PND, que pode agora frequentar ações de formação promovidas quer pelo Centro de Formação da Associação de Escolas (CFAE), a que pertence o $A E$, quer pela autarquia. Porém, compete ao órgão de gestão da escola fazer a respetiva avaliação do PND que pertence à autarquia, como consta na lei.

1 Unidade organizacional, dotada de órgãos próprios de administração e gestão, constituída por diferentes estabelecimentos de educação. 
Mais recentemente, no âmbito do programa "Aproximar Portugal" implementado pelo Governo, ocorreu a publicação do Decreto Lei $n$. $^{\circ}$ 30/2015, de 12 de fevereiro, o que (re)colocou na agenda dos diversos atores educativos o tema da "municipalização da educação". Esta iniciativa legislativa estabelece o regime de delegação de competências nos municípios e entidades intermunicipais no domínio de funções sociais, através da celebração de contratos interadministrativos, de forma gradual e faseada, através de projetos-piloto.

No que respeita à educação, esta nova iniciativa de delegação compreende as competências já anteriormente atribuídas aos municípios, mas também integra novas competências até agora atribuídas às escolas/ agrupamentos de escolas ou aos serviços do Ministério da Educação. Assim, o art. $^{\circ} 8^{\circ}$ identifica cinco domínios de delegação de competências: a) gestão escolar e das práticas educativas, b) gestão curricular e pedagógica, c) gestão dos recursos humanos, d) gestão orçamental e de recursos financeiros e e) gestão de equipamentos e infraestruturas do ensino básico e secundário.

\section{Estudo empírico}

É no contexto do processo da descentralização educativa e da crescente promoção política da municipalização da educação que nos propusemos responder à pergunta: Como se articulam a autarquia e a escola na gestão do PND?

Neste sentido, julgamos ser pertinente conhecer as representações que os coordenadores do PND, assistentes técnicos e assistentes operacionais, os gestores autárquicos e os órgãos de gestão do Agrupamento de Escolas construíram sobre a gestão do PND, em resultado do processo de descentralização educativa, por via da implementação do Contrato de Execução celebrado entre o Ministério da Educação e o município.

Com este estudo pretendemos identificar as dinâmicas de poder/decisão e, como consequência, problematizar a escola/Agrupamento como locus de tensão/conflito e/ou de colaboração. Foi, também, nosso objetivo perceber se o fator proximidade, em confronto com a centralidade, é potenciador de uma gestão de recursos humanos mais eficiente.

1. Neste contexto de partida formulamos algumas sub-questões que assumiram uma dimensão orientadora e exploratória do nosso objeto de estudo:

2. Que razões levaram a autarquia a aderir ao Contrato de Execução?

3. Na gestão do PND, quais as competências que a autarquia delega nas lideranças escolares?

4. O recrutamento dos recursos humanos a nível local é suscetível de ser influenciado por fatores subjetivos, vulgo "clientelismo"?

5. A municipalização da gestão do PND traduz-se na perceção de ganhos de produtividade e eficiência para a instituição escola/ agrupamento?

6. As "tensões político-partidárias" a nível local têm reflexos na praxis gestionária do PND?

A investigação assumiu a forma de estudo de caso por proporcionar a possibilidade de analisar indutivamente uma situação concreta e circunstanciada, revelando-se apropriada para realizar "um exame detalhado e completo de um fenómeno ligado a uma entidade social" (Fortin, Côté \& 
Filion, 2009, p. 241), de resto, opção adequada quando não existem muitos dados disponíveis sobre o fenómeno em análise, sendo que potencia o "caminho para estudos de maior envergadura" (Fortin, Côté \& Filion, 2009, p. 242).

A consideração de uma única unidade de gestão/autarquia para a realização do nosso estudo, que encontra justificação na limitação temporal de que dispúnhamos, muito embora afaste a generalização em sentido lato e abstrato, admite uma generalização de resultados dita restritiva e naturalista que será suportada na comparação que o leitor poderá fazer relativamente aos seus contextos, à sua situação concreta. Ora, tal pressuposto não constitui a negação da validade e da importância destes estudos, na medida em que, como escreve Anne Laperrière "o rigor [destes estudos] vem, então, da solidez dos laços estabelecidos entre nossas interpretações teóricas e nossos dados empíricos" (1997, p. 375).

Com efeito, o estudo de caso, enquanto estratégia de pesquisa, possibilita a utilização de diferentes técnicas de investigação, como seja a entrevista semiestruturada, que foi efetuada durante os anos de 2015 e 2016, num município e num Agrupamento de Escolas, situados no interior norte de Portugal.

Assim, procuramos que os resultados do nosso estudo fossem alicerçados pela revisão de literatura, enquadrando-os em teorias mais abrangentes, e validados pela comparação com outros estudos já realizados sobre a mesma temática com objetivos similares.

É de salientar que são muito parcos os estudos realizados, especificamente, sobre a temática da gestão do PND, no âmbito da descentralização de competências para os municípios, expressa nos contratos de execução celebrados entre o Ministério da Educação e os municípios. Se é possível afirmar que esta é uma problemática muito recente, também é justo dizer que o PND é um grupo de profissionais pouco valorizado nas investigações levadas a cabo, o que pode justificar a falta de protagonismo que tem granjeado e que parece reforçar a ideia de "parente pobre" do sistema educativo.

Segundo dados dos censos de 2011, o concelho tem 14 freguesias e 8 aldeias anexas, com uma população de 6690 habitantes, dos quais 2264 vivem na sede do concelho.

De acordo com os dados do ano letivo 2014-2015, a população escolar do município totaliza 656 alunos.

O Contrato de Execução implicou a integração nos quadros do pessoal do município o Pessoal Não Docente até então pertencente ao quadro do Ministério da Educação. Da lista constante do anexo ao Contrato de Execução, à época, passaram a ser tutelados pelo município 51 funcionários (43 assistentes operacionais e 8 assistentes técnicos). Estes funcionários juntaram-se aos que o município então contratava para suprir necessidades nas escolas do ensino pré-escolar e do $1^{\circ}$ ciclo do ensino básico.

Os dados empíricos colhidos foram tratados com recurso à técnica da análise de conteúdo (Quivy \& Campenhoudt, 1992), que implica uma rutura epistemológica face à intuição aleatória e à superficialidade que permitam a mera subjetividade analítica.

Recorremos a esta técnica para determinar os padrões de comportamento, os temas e as relações, que de forma analítica foram filtrados e classificados de acordo com os objetivos da nossa investigação. Desta forma dispusemos as evidências numa matriz de categorias para poder indutivamente inferir algumas conclusões. 
Quadro 1

Categorias de análise de dados

\begin{tabular}{|c|c|c|c|c|}
\hline \multicolumn{2}{|c|}{ Domínios } & \multicolumn{2}{|c|}{ Categorias } & \multirow{2}{*}{$\begin{array}{l}\text { Subcategorias } \\
\text { - "Convite/pressões" } \\
\text { - Reconhecimento formal de competências }\end{array}$} \\
\hline \multirow{3}{*}{1} & \multirow{3}{*}{$\begin{array}{l}\text { Adesão ao Contrato } \\
\text { de Execução }\end{array}$} & A1 & Razões da adesão & \\
\hline & & A2 & Intervenientes no processo & $\begin{array}{l}\text { - Os signatários } \\
\text { - Os excluídos } \\
\text { - Os resistentes }\end{array}$ \\
\hline & & A3 & Contrapartidas negociadas & $\begin{array}{l}\text { - Formais } \\
\text { - Informais }\end{array}$ \\
\hline \multirow{3}{*}{2} & \multirow{3}{*}{$\begin{array}{l}\text { Exercício da } \\
\text { competência da } \\
\text { gestão do Pessoal } \\
\text { Não Docente }\end{array}$} & B1 & Competências delegadas & - Despacho do presidente da Câmara Municipal \\
\hline & & B2 & Recrutamento & $\begin{array}{l}\text { - Abertura de vagas reportadas ao Ministério da Educação } \\
\text { - Perda de competências do Agrupamento de Escolas } \\
\text { - Câmara Municipal como "barriga de aluguer" } \\
\text { - Contratação extra rácio }\end{array}$ \\
\hline & & B3 & Gestão quotidiana & $\begin{array}{l}\text { - Perfil da pessoa para as funções a desempenhar } \\
\text { - Desempenho temporário de funções } \\
\text { - Disponibilidade pontual de recursos humanos }\end{array}$ \\
\hline \multirow[b]{2}{*}{3} & \multirow{2}{*}{$\begin{array}{l}\text { Racionalidade } \\
\text { decisória das } \\
\text { lideranças } \\
\text { autárquica e } \\
\text { escolar. }\end{array}$} & C1 & As tomadas de decisão & $\begin{array}{l}\text { - Visão legalista e burocratizada } \\
\text { - Acomodação de interesses particulares }\end{array}$ \\
\hline & & $\mathbf{C 2}$ & $\begin{array}{l}\text { As relações entre líderes e } \\
\text { instituições locais }\end{array}$ & $\begin{array}{l}\text { - Colaboração institucional } \\
\text { - Momentos de tensão pessoal relacionados com a } \\
\text { disputa autárquica }\end{array}$ \\
\hline
\end{tabular}

Fonte: elaboração própria

Para as entrevistas construímos um guião com questões orientadoras que visavam obter informações pertinentes e relevantes de acordo com os objetivos específicos, traçados para a nossa investigação.

Quadro 2

Objetivos específicos das entrevistas

1. Compreender o processo de negociação que conduziu à celebração do Contrato de Execução entre o Ministério da Educação e a Câmara Municipal.

1.1. Conhecer os motivos que levaram à celebração do Contrato de Execução entre o Ministério da Educação e a Câmara Municipal.

1.2. Identificar os intervenientes e a sua contribuição na celebração do Contrato de Execução.

1.3. Saber se o Pessoal Não Docente foi ouvido no decurso da negociação entre o Ministério da Educação e a Câmara Municipal.

1.4. Perceber a importância atribuída à competência de gestão do Pessoal Não Docente, comparativamente com as restantes competências descentralizadas, no contexto do Contrato de Execução.

2. Conhecer, na prática, o processo de gestão do Pessoal Não Docente no âmbito da implementação do Contrato de execução.

2.1. Identificar as competências delegadas pelo presidente da autarquia no diretor do Agrupamento de Escola.

2.2. Compreender as razões para não delegar alguma(s) competência(s).

2.3. Saber quem e como é gerido diariamente o Pessoal Não Docente.

2.4. Perceber como são colmatadas as situações de carência de Pessoal Não Docente.

2.5. Reconhecer as vantagens para o Pessoal Não Docente, o Agrupamento de Escolas e a Câmara Municipal, resultantes da implementação do Contrato de Execução.

3. Perceber a articulação que existe entre as lideranças da Câmara Municipal e do Agrupamento de Escolas, no exercício da competência de gestão do Pessoal Não Docente.

3.1. Identificar possíveis conflitos e/ou divergências entre as lideranças da Câmara Municipal do Agrupamento de Escolas.

3.2. Saber se os interesses individuais e/ou as tensões políticas locais influenciam a praxis gestionária das lideranças.

Fonte: elaboração própria 
No âmbito desta investigação realizamos 7 entrevistas semiestruturadas a pessoas que desempenham cargos de liderança de topo ou intermédia nas instituições Câmara Municipal e Agrupamento de Escolas.

Quadro 3

Entrevistas realizadas

\begin{tabular}{l|l|c}
\hline \multicolumn{2}{l|}{ Funções } & Entrevista \\
\hline \multirow{4}{*}{$\begin{array}{l}\text { Agrupamento } \\
\text { de Escolas }\end{array}$} & Diretor do Agrupamento de Escolas & E1 \\
\cline { 2 - 3 } & Presidente do Conselho Geral & E2 \\
\cline { 2 - 3 } & Coordenadora técnica & E3 \\
\cline { 2 - 3 } & Coordenadora operacional & E4 \\
\hline \multirow{4}{*}{$\begin{array}{l}\text { Câmara } \\
\text { Municipal }\end{array}$} & Presidente da Câmara Municipal & E6 \\
\cline { 2 - 3 } & Vereadora com o pelouro da Cultura e Educação & E7 \\
\cline { 2 - 3 } & $\begin{array}{l}\text { Presidente da Assembleia Municipal/ } \\
\text { Ex-presidente da Câmara }\end{array}$ & \\
\hline \hline
\end{tabular}

Fonte: elaboração própria

A seleção das pessoas entrevistadas obedeceu a um processo de escolha intencional, de acordo com os cargos de liderança desempenhados na autarquia e no Agrupamento de Escolas.

\section{Os dados}

\section{Adesão ao Contrato de Execução}

A negociação do Contrato de Execução entre o município e o Ministério da Educação obedeceu a uma lógica top down, partindo mais da iniciativa da administração central e não tanto do desejo ou reivindicação da comunidade local. Tratou-se de um processo despoletado pela administração central e fomentado pelas estruturas desconcentradas de então, concretamente a Direção Regional de Educação do Norte, que procurou aligeirar as suas responsabilidades, nomeadamente financeiras, a pretexto de descentralizar competências e de aproximar as decisões dos cidadãos.

A1 - Raz̃ões da adesão

Estamos perante um processo ao qual a autarquia aderiu "convidada" pela então diretora regional de educação, pois, como expressa o E5:

Nós aderimos, não digo pressionados, mas foi um convite, teria sido um convite com um jeitinho. Há uma intenção de conseguirem, nesta nova relação entre o ministério e as autarquias, com a educação pelo meio, celebrar estes acordos de execução.

No mesmo sentido podem ser interpretadas as palavras do E7, quando afirma que "Houve uma série de pressões para assinar". No entanto, também ressalva que, sendo de opinião que "Um protocolo desses seria de facto vantajoso para a escola, para as crianças, para os jovens, para os trabalhadores da escola, efetivamente para todos. Só não seria de facto vantajoso para o presidente da Câmara", a assinatura do Contrato de Execução configurava-se uma boa opção para a comunidade local.

Esta perspetiva é corroborada pela E6 quando refere que "o interesse partiu do ministério. A Câmara foi convidada. O maior interesse não era da Câmara, era do Ministério da Educação". 
Por outro lado, na perspetiva do E7, o Contrato de Execução tinha, ainda, o mérito de reconhecer formalmente à autarquia competências que desde há muito já assumia, substituindo-se ao então Ministério da Educação. A este propósito esclarece que:

Desde sempre, antes mesmo dos protocolos existentes com o ME (Ministério da Educação), a escola tinha um relacionamento de ordem prática com a Câmara em que quando tinha uma necessidade qualquer, fosse a necessidade de modificar a fechadura de uma porta, seja a necessidade de substituir uma funcionária que está de baixa, etc., etc. Centenas e centenas de vezes a Câmara mandava pessoal para a escola, não tendo a própria Câmara pessoal. Ora bem, as ruas podiam ficar por varrer. Mas a escola era uma coisa muito particular para a Câmara, porque se trata de crianças. Trata-se do desenvolvimento harmonioso dessas crianças. Era assim.

Também neste âmbito, atendendo à cooperação que existia entre o município e o Agrupamento de Escolas, as transferências financeiras por parte do Ministério da Educação, para comparticipação nas despesas com a educação, era um aspeto que não podia deixar de ser considerado.

A adesão ao Contrato de Execução resulta de uma estranha conjunção de interesses organizacionais que, na prática, se traduziu na subalternização do poder autárquico ao poder central e no reconhecimento legal de competências que, até então, o município assumia de forma supletiva como extracompetências. Assim, numa perspetiva de regulação burocrática, o município valoriza a formalização do reconhecimento de competências por via da sua transposição para o Contrato de Execução.

Desta feita, refém de uma racionalidade burocrática, a autarquia, paradoxalmente, coloca-se (in)conscientemente na dependência da administração central, em relação à qual goza de autonomia, de acordo com a Constituição. O Contrato de Execução contribui, assim, para a reconfiguração do modelo organizacional do sistema de ensino, dando a possibilidade ao Ministério da Educação de passar a "tutelar" a autarquia, vista agora como nova instância periférica/local da administração, na qual delegou competências.

\section{A2 - Intervenientes no processo}

O processo que conduziu à celebração do contrato, que define as condições de transferência de competências para o município, desenvolveu-se com alguma rapidez e foi pouco participado, porque foi decidido apenas por dois dos agentes educativos implicados, ou seja, os signatários. Embora fossem partes interessadas, é significativo que tanto os órgãos de gestão do Agrupamento de Escolas como o PND tenham sido mantidos à margem de todo o processo negocial. É, pois, natural que o mesmo seja merecedor de algum descontentamento por partes destes atores educativos. Assim se percebem as palavras do E1 quando afirma que:

a única auscultação feita, e essa de forma muito informal, foi do presidente da Câmara da altura que procurou saber junto de mim, na qualidade de diretor, qual era a minha opinião sobre esse eventual Contrato de Execução. Então, aí sim, dei a minha opinião. Da parte do ministério, [...] mas isso já foi tardiamente, na altura da assinatura dos contratos de execução, houve um convite apenas para estar presente em Lisboa. Por razões óbvias, não estive. 
A mesma informação é veiculada pelo E2 ao salientar que "Antes do processo ter sido aprovado nunca chegou qualquer informação às escolas para haver qualquer debate, qualquer parecer sobre a questão. Nunca ninguém perguntou a opinião, parecer sobre a municipalização ao conselho geral".

O mesmo descontentamento transparece quando a E3 expressa o seu sentir:

Isto nós nunca somos ouvidos ou achados para nada. Quando nos transmitiram já iríamos transitar a 1 de janeiro. Ninguém nos perguntou se queríamos, se não queríamos, os prós e os contras eram estes e aqueles e nós manifestarmos se queríamos ou não. Foi um facto consumado.

Como podemos depreender, o processo negocial que conduziu ao Contrato de Execução excluiu importantes atores educativos, nomeadamente o PND a quem foi alterada a tutela da sua gestão.

Também estranhamos a não implicação do Conselho Geral nas negociações, enquanto órgão representativo de toda a comunidade educativa. Este facto é bem elucidativo de que são financeiras as verdadeiras razões do Ministério da Educação quando procura promover a descentralização de competências, por via da contratualização com os municípios. Neste cenário temos de reconhecer, impotentes, que a racionalidade económica impera e sobrepõe-se às pessoas.

Da análise feita não podem ser excluídas outras razões para a desvalorização da participação da comunidade educativa e das estruturas de gestão da escola na negociação. Neste domínio, não é de desconsiderar a aprendizagem histórica resultante das anteriores tentativas de implementação da descentralização. Esta diz-nos que a descentralização foi sempre objeto da resistência corporativista da classe docente (Nóvoa, 2005). Classe que continua a manter um grande peso na gestão das escolas.

Não menos importante, uma outra razão terá sido a débil preparação da generalidade dos atores educativos para, de forma construtiva, darem o seu contributo num processo negocial que efetivamente descentralizasse competências para o poder local.

Note-se que o tema da descentralização, por via da municipalização, volvidos 8 anos da publicação do Decreto Lei n. ${ }^{\circ}$ 144/2008, de 28 de Julho, e consequente assinatura dos contratos de execução, ganhou um novo ânimo com a discussão em torno do Decreto Lei n. ${ }^{\circ}$ 30/2015, de 12 de fevereiro. Contudo, talvez reflexo das tentativas anteriores que sempre a foram anunciando mas, na prática, apenas procuraram desconcentrar serviços aproximando-os dos cidadãos, continuamos a deparar-nos com o cenário de sempre, ou seja, mantém-se a oposição acérrima dos sindicatos de professores e têm proliferado os debates e sessões de esclarecimento sobre o tema.

\section{A3 - Contrapartidas negociadas}

No decurso do processo negocial, o ímpeto descentralizador do governo foi aproveitado pela autarquia para negociar algumas contrapartidas financeiras com o intuito de procurar melhorar e requalificar certos espaços escolares.

A autarquia obteve o acordo com o Ministério da Educação para a transferência anual do montante de 20.000 , para manutenção e apetrechamento da escola básica e secundária.

Mas é reconhecido que nem todas as contrapartidas negociadas e aceites pelo Ministério da Educação foram concretizadas. Na verdade, 
como nem todas ficaram inscritas no Contrato de Execução, alude-se, pelo menos, a duas contrapartidas que nunca chegaram a materializar-se.

Como explica o E5:

Havia também uma intenção, na altura nós estávamos a construir, mas foi uma intenção que não ficou firmada no papel, havia um compromisso de nos comparticiparem um investimento que estávamos a fazer num centro escolar de uma freguesia, que nunca foi concretizado.

No mesmo sentido, o E7 revela que na negociação foram acordadas verbas que nunca chegaram a ser disponibilizadas pelo ministério ao município. Este interveniente no processo esclarece que na negociação com a diretora regional de educação, atendendo aos problemas infraestruturais da escola básica e secundária, fez saber que havendo:

meia dúzia de problemas a resolver, [...] nós assinaríamos o protocolo se ficasse explícito no protocolo as verbas necessárias para efetuar os arranjos. Eram $200.000 €$ para resolver os problemas de saneamento, etc. A senhora diretora [...] nos últimos dias antes da assinatura entra em contacto connosco dizendo que o dinheiro não podia ficar no protocolo... fizemos asneira.

Também conhecedor dos problemas infraestruturais da escola básica e secundária, o E1 manifestou muitas reservas quanto à assinatura do Contrato de Execução, tendo oportunamente alertado o então presidente da Câmara Municipal para o facto:

de estar a celebrar um Contrato que não fosse muito vantajoso para a autarquia, já que estava a receber todo um parque escolar com alguns anos de idade e que precisariam de obras de grande monta. Alertei o senhor presidente da câmara para ele ter a noção daquilo que estaria, passe a expressão, a herdar.

A verdade é que as expetativas do executivo camarário quanto às contrapartidas negociadas não foram inteiramente correspondidas. Algumas delas nunca chegaram aos cofres do município, o que leva o E7 a reconhecer que "Alguma coisa falhou depois. E o que faIhou depois foi a crise que chegou. Eu penso que se não houvesse crise uma série de obras já se teriam feito".

Também não é menos significativa a necessidade da autarquia continuar a contratar recursos humanos, utilizando verbas do orçamento municipal, para colmatar as necessidades de Pessoal Não docente das escolas do concelho, pois o rácio estabelecido pelo Ministério da Educação é insuficiente. Como enfatiza o E5: "nós além dos rácios temos muita mais gente, que é nossa".

Analisando as preocupações que levaram a autarquia a solicitar algumas contrapartidas no decorrer do processo negocial, podemos concluir que do leque de competências transferidas para o município, previstas no âmbito do Contrato de Execução, ao abrigo do Decreto Lei n. ${ }^{\circ}$ 144/2008, de 28 de Julho, a gestão do PND foi completamente subalternizada relativamente a outras, nomeadamente a gestão do parque escolar e das verbas que lhe foram destinadas para manutenção e apetrechamento. De facto, a não ser assim, como compreender que o município, no decurso do processo negocial, não tenha solicitado qualquer montante adicional para contratação de PND? Estranha-se este facto, tanto mais que era ao município que o Agrupamento de Escolas recorria sempre que tinha carência de PND.

\section{Exercício da competência da gestão do PND}

Da implementação do Contrato de Execução, no que concerne à competência da gestão do PND, resulta a perceção generalizada de que na prática nada de relevante se alterou.

As necessidades do PND deixaram de ser reportadas ao Ministério da Educação, sendo agora transmitidas à Câmara Municipal. Com este intuito, no início de cada ano letivo, decorre uma reunião entre a vereadora da autarquia, com o pelouro da cultura e educação, e uma adjunta da direção do Agrupamento de Escolas, para se proceder ao levantamento de eventuais necessidades de PND nas escolas do agrupamento. De forma complementar, sempre que se verificam ausências pontuais e imprevistas, a direção do Agrupamento de Escolas coloca o problema à Câmara Municipal, que o procura solucionar. Neste cenário obtiveram-se ganhos inerentes a uma comunicação mais próxima e direta com os decisores.

Vistas assim as coisas, no essencial, o diretor do Agrupamento de Escolas mantém sensivelmente as mesmas competências que tinha antes do Contrato de Execução, embora não se coíba de expressar a convicção de que "perdeu claramente competências".

Tentando perceber a forma como é feita a gestão do Pessoal Não Docente procuramos explorar algumas dimensões tidas como relevantes na sua implementação.

\section{B1 - Competências delegadas}

O Contrato de Execução, assinado com o Ministério da Educação, e o Decreto Lei n. ${ }^{\circ}$ 144/2008, de 28 de Julho, conferem à autarquia o poder de decisão sobre a competência de gestão do PND, podendo concentrá-la ou, então, partilhá-la com os órgãos de gestão dos agrupamentos. 
Neste enquadramento, ao abrigo do ponto 4 , do art. ${ }^{\circ}{ }^{\circ}$, do Decreto Lei n. ${ }^{\circ}$ 144/2008, de 28 de Julho, com exceção do recrutamento, as competências da gestão do PND foram delegadas no diretor do Agrupamento de Escolas, por despacho do presidente da Câmara Municipal.

O E1 confirma esta situação quando diz que "o recrutamento não está delegado. Isto através de um despacho do senhor presidente da câmara". Este facto não deixa de suscitar alguma estranheza, tanto mais que para o mesmo interlocutor nada o impede que a competência de recrutamento seja delegada, pois, não deixa de informar que "no próprio Decreto-Lei está prevista essa delegação".

A delegação das restantes competências configura-se mais pacífica e natural perante a constatação de que são os órgãos de gestão do Agrupamento de Escolas, porque mais próximos, quem pode fazer de forma mais eficaz a gestão quotidiana do PND, ou não fosse a escola o seu local de trabalho. A este propósito o E1 veicula a opinião "que não seria muito fácil dirigir um agrupamento onde a afetação, a colocação de pessoal, bem como o poder disciplinar, não estivesse nas mãos do diretor do agrupamento".

\section{B2 - Recrutamento}

E sendo possível², a não delegação, no diretor do $A E$, da competência de recrutamento configura-se um ponto sensível na articulação entre a autarquia e a escola da gestão do PND. Estamos claramente perante uma opção que, não decorrendo forçosamente da legislação, se enquadra no domínio do exercício político e num modelo de exercício pessoal da liderança.

A este propósito, resignado, o E1 lembra que a não delegação da competência de recrutamento do PND "foi uma opção. Não foi discutido sequer".

Como é natural, não delegando, o E5 pensa de forma diferente: "O recrutamento não pode ser feito pela escola. Eles comunicam e nós fazemo-lo. Pela razão de que se houver uma denúncia do contrato quem vai ter que os suportar somos nós".

Apesar de contratualmente ter a competência da gestão do PND, a Câmara Municipal continua a reportar burocraticamente ao Ministério da Educação a decisão de abrir vagas para recrutamento de pessoal ao abrigo do rácio estabelecido. Só assim se entende a atuação do E5 quando reconhece adotar uma atitude defensiva, ao perguntar "sempre ao ministério se estão dentro dos rácios, porque um dia qualquer que a câmara entenda denunciar o contrato é nosso entendimento que essas pessoas deveriam [...] fazer parte do quadro do Ministério da Educação". Para este ator esta atitude explica-se pelo reivindicar de um relacionamento mais firme e claro com o ministério e pela defesa de que se "estes contratos não são ad eternum, um dia podem vir a ser denunciados".

É no contexto da opção por uma gestão cautelosa, a coberto do princípio da racionalidade burocrática, que podemos compreender a não delegação da competência de recrutamento do PND no Diretor do Agrupamento de Escolas. Desta forma, o líder autárquico, ao não perder o controlo sobre o processo de contratação, procura afastar qualquer possibilidade de contaminação emocional passível de levar ao desrespeito do rácio contratualmente definido. Esta ideia transparece quando o E5, invocando uma futura hipotética denuncia do contrato, afirma que "quem terá de os suportar somos nós".

2 Ao abrigo do ponto 4, do art. ${ }^{\circ}{ }^{\circ}$, do Decreto Lei n. ${ }^{\circ}$ 144/2008, de 28 de Julho. 
Esta situação leva o diretor do Agrupamento de Escolas a formular a convicção de que, com a implementação do Contrato de Execução, a escola perdeu competências a favor do município. Antes a escola dialogava diretamente com o ministério. O Agrupamento de Escolas solicitava a autorização para desencadear a abertura do concurso para admissão de PND. Hoje tem de dialogar com o município, o qual se assume como uma estrutura local do Ministério da Educação.

O recrutamento do PND, ao abrigo do rácio, obedece agora a uma lógica tripartida. O Agrupamento de Escolas deteta a necessidade de preencher o(s) lugar(es), a Câmara Municipal implementa o processo de seleção dos candidatos através de concurso e o Ministério da Educação informa da disponibilidade de vaga. A Câmara Municipal faz depender a abertura do concurso de parecer favorável do Ministério da Educação. Desta forma, não assume na plenitude a competência que contratualizou com o ministério. Embora tendo a autonomia legal e financeira para poder decidir preencher as lacunas de PND, na verdade, neste domínio, o município age como uma estrutura periférica do Ministério da Educação (Fernandes, 2005).

Podemos depreender que a autarquia ainda não acomodou de forma plena o PND, transferido ao abrigo do Contrato de Execução, no âmbito dos seus recursos humanos. Nas palavras do seu líder, este assume-se como "barriga de aluguer" (E5), ao serviço do Ministério da Educação, quando disponibiliza os recursos humanos para desempenhar funções não docentes no Agrupamento de Escolas. A vereadora da autarquia transmite esta ideia quando explica que "Eles são funcionários da Câmara Municipal, sem dúvida, mas [...] de facto são funcionários do Ministério da Educação. É que se um dia a câmara rescindir o acordo, eles terão de ser transferidos para lá na mesma" (E6).

No entanto, fazendo jus à sua natureza política, a Câmara Municipal disponibiliza, extra rácio, assistentes operacionais para desempenhar funções de PND. A contratação por tempo determinado deste pessoal permite suprir as carências pontuais e imprevistas de PND do Agrupamento de Escolas. Neste caso, o processo de recrutamento é totalmente da responsabilidade do município. É o município que controla todo o processo. O júri de seleção e recrutamento é exclusivamente constituído por elementos da autarquia. Como informa a E6 o júri é "o nosso pessoal. Geralmente escolhemos pessoas com muita experiência", referindo ser assim porque "o pessoal quando é selecionado não é selecionado para o Agrupamento de Escolas, mas para o município. Depois nós pegamos na 'Maria' e no 'António' e pomos lá".

Tratando-se de PND recrutado para desempenhar funções no Agrupamento de Escolas, seria de esperar que o diretor tivesse uma palavra a dizer no processo. Tal não sucede, sendo-lhe a nosso ver, neste aspeto, atribuído (in)formalmente o papel de simples coordenador deste PND.

Nada impede que todo o PND, intra ou extra rácio, seja recrutado com recurso ao mesmo procedimento. Contudo, tal não é a opção e a mesma não é claramente explicada ou assumida. Assim, é nossa interpretação que esta se explica pelo jogo político comummente atribuído ao poder local autárquico. Num concelho de pequena dimensão e carente de postos de trabalho, como é o caso, não é totalmente displicente a possibilidade de poder contratar mais recursos humanos, alargando por essa via a área de influência a maior número de população/munícipes. Estamos perante uma situação em que os interesses individuais e políticos, facilmente, se podem sobrepor aos interesses/objetivos da organização que é o Agrupamento de Escolas. 
B3 - Gestão quotidiana: afetação e colocação do pessoal

Como já constatamos, com o despacho do presidente da Câmara Municipal, a maioria das competências de gestão do PND passam a ser assumidas pelo diretor do Agrupamento de Escolas, nomeadamente a afetação e colocação do pessoal.

Atendendo ao processo de recrutamento, podemos dizer que o Agrupamento de Escolas conta com dois tipos/grupos de recursos humanos para desempenhar as funções de PND.

A situação de no Agrupamento de Escolas coabitarem dois grupos de PND cria alguns constrangimentos aquando da distribuição de funções. Como refere o E1:

Todo aquele pessoal que trabalha numa escola, seja PND ou docente, deveria ter todo ele formação. [...] termos alguém que venha pontualmente trabalhar numa escola, isso condiciona, como é evidente [...]. Eles desempenham funções que são inerentes a assistentes operacionais. Agora temos é algum cuidado, muito particular, com o lugar onde eles são colocados. Por vezes, na cozinha, um setor fundamental e onde há dificuldades de funcionamento se houver baixas imprevistas, não há aí um contacto muito direto com alunos, e também noutras tarefas menos diferenciadas, como são por exemplo a limpeza.

A E4 corrobora esta situação explicando que "temos que ver o perfil da pessoa, se é mais adequado para estar naquele setor ou no outro. Se é nova na escola, temos inicialmente algum cuidado e, por isso, evitamos dar-lhe funções de alguma responsabilidade ou de contacto direto com os alunos".

Também não deixa de apontar como negativo outro condicionalismo inerente ao desempenho temporário de funções de assistente operacional. O trabalho de formação e adaptação, a quem chega de novo, às funções específicas de assistente operacional é constante, aspeto que a leva a lamentar-se: "às vezes vêm uns dias, uma semana ou um mês, quando estão a aprender vão embora".

Contudo, não podemos escamotear que, num contexto de significativo absentismo que se tem registado, tal expediente tem-se revelado bastante benéfico para o Agrupamento de Escolas. Como refere o E5 "o agrupamento consegue ter funcionários, não cumprindo os rácios, fruto de uma maior capacidade de reivindicação junto da câmara". Sem esta disponibilidade pontual de recursos humanos, em determinados momentos, seria muito difícil às lideranças escolares gerir serviços vitais do agrupamento. Neste domínio é consensual que o Contrato de Execução tem vantagens para o Agrupamento de Escolas.

\section{Racionalidade decisória das lideranças autárquica e escolar}

Como é compreensível a praxis gestionária da autarquia e do Agrupamento de Escolas obedecem a lógicas e objetivos nem sempre convergentes em todas as situações. Estamos perante organizações distintas e com diferentes formas de legitimação das lideranças. Daqui decorre que, como sabemos, a autonomia decisória do líder autárquico é incomparável à do diretor de um Agrupamento de Escolas. Excluindo a dimensão legal, o autarca responde perante os seus eleitores/munícipes, já o diretor responde, sobretudo, perante o (ciber)controlo cada vez mais asfixiante de uma administração central assumidamente legalista e burocrática.

\section{C1 - As tomadas de decisão}

Se considerarmos algumas tomadas de decisão aqui referidas podemos afirmar que, no contexto da gestão do Pessoal Não Docente contratualizada com os municípios, o processo decisório sofre uma dupla influência: da asfixia própria de uma racionalidade burocrática - decorrente dos normativos legais e no controlo de uma administração centralizada - e do jogo conciliatório de interesses que levam e atores locais a negociar alianças de poder.

Neste âmbito, identificamos nas lideranças municipal e do Agrupamento de Escolas uma visão legalista e burocratizada do exercício da competência de gestão do PND, a espaços matizada com tomadas de decisão de caráter político, procurando sempre contribuir para um contexto socioeducativo que promova o sucesso educativo dos munícipes numa perspetiva integral e integradora.

Sem pretender ser demasiado rígido ou purista quanto à classificação, podemos considerar que ilustram decisões predominantemente legalistas e formais a preocupação constante em não ultrapassar o rácio do PND contratualizado com o Ministério da Educação; a delegação de competências sem uma negociação prévia com o diretor do Agrupamento de Escolas; um certo formalismo institucional nas relações entre as lideranças. Por outro lado, podemos referir que outras decisões denotam alguma acomodação de interesses particulares ou decorrem de processos negociais, nomeadamente a disponibilização pela autarquia de pessoal para o Agrupamento de Escolas poder suprir carências pontuais e imprevistas, num espírito de colaboração e assumindo um papel supletivo; a celebração do Contrato de Execução com o Ministério da Educação; o processo de recrutamento do PND. 
C2 - Relacionamento entre as lideranças da câmara e da escola

Tradicionalmente nos meios mais pequenos as disputas políticas podem ser mais inflamadas e despoletar tensões ou conflitos entre os opositores.

Confessamos que, desde o início, tínhamos algumas expetativas em saber qual o relacionamento entre as lideranças das duas estruturas organizacionais, pelo facto de no último ato eleitoral autárquico o atual presidente da Câmara Municipal e o diretor do Agrupamento de Escolas serem opositores políticos. Esta situação levou-nos a procurar saber como se relacionam estas lideranças no contexto institucional.

Tanto o presidente da autarquia como o diretor do Agrupamento de Escolas procuram transmitir a ideia de normalidade nas relações que mantêm. Salientam o espírito de colaboração e comprometimento na resolução dos problemas que vão surgindo no Agrupamento de Escolas. No entanto, transparece das suas palavras estarem conscientes de alguma reserva que vão procurando na sua praxis gestionária.

Assim, é revelador que o E5 assuma que o ter disputado umas eleições com o diretor do Agrupamento de Escolas o leva "a ter com a escola um cuidado ainda acrescido".

Também o E1 reconhece que:

Há cuidado acrescido, sem dúvida. Sem dúvida. Tenho um cuidado acrescido, em que as minhas posições não possam ser interpretadas noutro sentido, legitimamente ou não [...]. Concordo nisso, sem dúvida, de que reflito sempre com muito mais cuidado nas minhas tomadas de posição, mesmo a nível institucional.

Este cuidado pessoal redobrado adquire maior relevo se tivermos o entendimento de que o perfil pessoal tem maior peso no desempenho de cargos institucionais do que propriamente as questões político-partidárias. Nos meios pequenos, muito mais que a filiação política e partidária, os cargos ou funções são condicionados pela personalidade de quem os exerce. Ao refletir sobre esta questão, o E1 perfilando esta ideia reconhece que: "esse é um dos meus grandes receios nestes contratos de execução [...]. Eu acho que as coisas ficam muito dependentes, por vezes, da pessoa que ocupa determinado lugar muito mais, para mim, do que o partido". E concretiza este seu pensar com um exemplo:

Neste Contrato de Execução está previsto [...] a transferência anual de $20.000 €$ para obras de manutenção, reparação e apetrechamento da EB2,3/S. O senhor presidente da câmara de então, quando foi celebrado o contrato, em conversa comigo, concordamos num acordo de cavalheiros, digamos, em que ele faria a transferência da totalidade da verba para a escola [...]. E assim se manteve isto até que o presidente da câmara teve a infelicidade de adoecer [...], não podendo exercer as funções, tendo sido naturalmente substituído pelo seu vice-presidente [...] que pôs logo em causa esta decisão e no primeiro ano [...] transferiu zero. E, a partir daí, passou a transferir $50 \%$.

Apesar de se poderem observar algumas divergências latentes, nas entrevistas tanto o presidente da Câmara Municipal como o diretor do Agrupamento de Escolas defendem que as relações entre si são de respeito, proximidade e colaboração institucional. No seu relacionamento institucional consideram que nada de relevante se alterou antes, durante ou após a disputa autárquica. 
Num sentido ligeiramente divergente podem ser compreendidas as palavras do presidente do conselho geral e do ex-presidente do município. Estes interlocutores têm a perceção que existiram momentos de tensão entre as duas lideranças, do município e agrupamento, e os dois opositores políticos candidatos ao cargo de presidente da câmara municipal.

Assim, o E2, não deixa de reconhecer algum mal-estar, quando diz:

É evidente que a escola está no contexto e não está à margem do contexto. [...] Uma vez que faziam parte do conselho geral dois candidatos à câmara acabou por se notar nas intervenções que ambos faziam. A oposição entre ambos era transportada também para ali. Digamos que o conselho geral, durante pelo menos algum tempo, foi palco de alguma conflitualidade fruto do contexto. Via-se que havia ali alguma coisa. As intervenções estavam a ser condicionadas pelo contexto político.

O mesmo sentir revela o E7 que, referindo-se à candidatura do diretor do Agrupamento de Escolas à presidência da autarquia, relata:

Houve um choque ou dois, que eu tive com ele, mais por razões formais do que outra coisa. O choque maior foi já quando estava a candidatura definida. Aí apercebi-me que havia um determinado aproveitamento da situação. Aí tive que cortar. [...] O que me aborrecia nele era isto [...], por exemplo, havia uma cerimónia de entrega de diplomas aos alunos do $12^{\circ}$ ano, a partir do momento em que convida o presidente da câmara, que num certo sentido tutela a escola, ele é obrigado a dar-lhe relevo na cerimónia. Não deu a primeira vez, nunca mais deu que eu nunca mais lá fui. [...] Estou convencido que essas situações se explicam pelo confronto político que então existiu.

Contudo, a análise aos dados recolhidos não é propensa a extrair qualquer conclusão legitimadora da existência de conflitos intencionais ou manifestos. Existiram, de facto, momentos de tensão pessoal explicáveis pela necessidade de afirmação política, compreensível e inerente a uma candidatura autárquica.

Ressalve-se que todos os entrevistados são unanimes em afirmar que as relações entre Câmara Municipal e o Agrupamento de Escolas primam pela curialidade, proximidade e espírito colaborativo. Ao assumir e promover este relacionamento, todos procuram efetivamente contribuir para solucionar os problemas com que o Agrupamento se vai deparando.

No entanto, não escamoteando as informações do E2 e do E7, é inegável que, perante o aproximar da disputa política, não deixaram de ocorrer momentos de tensão latente, explicados naturalmente pelas legítimas aspirações que, enquanto cidadãos, estes dois líderes tinham e possivelmente ainda têm.

Saliente-se, também, que a disputa autárquica deixou marcas indeléveis na atuação do E5 e do E1, que reconhecem ter ainda hoje, mesmo que inconscientemente, cuidados redobrados quando chamados a tomar determinadas decisões, procurando não ser mal interpretados pelas mentes mais "retorcidas" e "imaginativas" da comunidade local. Desta forma, a legítima e natural heterogeneidade de interesses pessoais não deixa de condicionar as lógicas de ação organizacional adotada por estes atores, no âmbito das suas margens de autonomia.

Em síntese podemos dizer que a ideia que subjaz à transferência de competências para as autarquias locais é o enriquecimento da sua missão e das suas competências. Fica instituído um nível político-educativo municipal 
que não seria possível num serviço local do estado e permite a participação dos diferentes intervenientes locais, um maior controlo político educativo e social por parte dos interessados.

Em termos de síntese podemos afirmar que, à semelhança do trabalho desenvolvido por Dinis António Sá Fernandes Pereira (2010), a nossa investigação revelou o caráter burocrático da gestão do PND, a adesão das autarquias ao contrato de execução sem qualquer poder negocial, o facto da mudança de entidade patronal ter apanhado de surpresa os membros do PND, devido à forma e à rapidez como ocorreu, a não identificação do PND como funcionários do município. De resto, e, apesar de continuar parcialmente "externa" à escola, existe a convicção que agora tudo se processa de forma mais célere, direta, frequente e cordial, produzindo-se assim uma maior eficiência na gestão do Pessoal Não Docente, com vantagens evidentes para a escola.

Teresa Seabra, Renato Carmo, Inês Baptista e Ana Fontes (2012), no estudo que realizaram e que incidiu sobre 6 municípios com contrato de execução com o Ministério da Educação, podemos destacar alguns traços comuns quanto às conclusões registadas, considerando que a maioria dos municípios opta por delegar o maior número possível de competências nos órgãos de gestão escolar, reconhecendo-os como a entidade mais indicada, pelo fator proximidade, para fazer a gestão quotidiana do PND. Fazem notar, que, numa tentativa de colmatar as necessidades das escolas, os municípios, em geral, procuram contratar PND em número excedente ao definido pelo rácio, recorrendo, para tal, a verbas próprias do Orçamento Municipal.

\section{Conclusão}

A recente opção pela municipalização, de acordo com os Decreto-Lei n. $144 / 2008$, de 28 de Julho, e o Decreto Lei $n^{\circ} 30 / 2015$, de 12 de fevereiro, procura conferir ao município um estatuto de charneira na determinação das políticas educativas locais.

Foi possível identificar nas práticas gestionárias do município e do Agrupamento de Escolas uma visão legalista e burocratizada do exercício da competência de gestão do Pessoal Não Docente, a espaços, matizada com tomadas de decisão de caráter político, procurando sempre contribuir para um contexto socioeducativo que promova o sucesso educativo dos munícipes numa perspetiva integral e integradora. É nesta perspetiva que deve ser entendida a decisão de celebração do Contrato de Execução. Apesar das "pressões" da administração central, este foi assumido como um instrumento de valorização e afirmação de poder da autarquia no domínio da educação.
Uma visão redutora e meramente instrumental do Contrato de Execução parece-nos preocupante se inferirmos que, do leque de competências transferidas para o município de acordo com o Contrato de Execução, a gestão do Pessoal Não Docente tem sido relativamente desvalorizada em favor de outras, nomeadamente a gestão do parque escolar e das verbas que lhe estão destinadas para manutenção e apetrechamento.

Como ponto mais sensível na articulação da gestão do Pessoal Não Docente identificamos a não delegação da competência de recrutamento no diretor do Agrupamento de Escolas, apesar de prevista no ponto 4, do art. ${ }^{\circ} 5^{\circ}$, do Decreto Lei n. ${ }^{\circ}$ 144/2008, de 28 de Julho. Neste âmbito, quanto ao processo de contratação do Pessoal Não Docente extra rácio, totalmente controlado pela autarquia, verifica-se que o diretor do Agrupamento de Escolas é ignorado, cabendo-Ihe apenas o papel de coordenador de funções. Na prática, este Pessoal Não Docente responde apenas perante o presidente da autarquia, que veem como o seu superior hierárquico, o que muito dificulta a sua integração e identificação com o Agrupamento de Escolas. Esta situação concorre para o aparente mal-estar latente que, por vezes, existe entre os dois "tipos" de pessoal, intra e extra rácio, que desempenham funções não docentes no Agrupamento de Escolas e, também, algum desconforto que o diretor do Agrupamento de Escolas sente quanto à gestão do Pessoal Não Docente extra rácio.

As relações entre as lideranças da autarquia e do Agrupamento de Escolas primam pela curialidade, proximidade e espírito colaborativo, procurando contribuir para solução dos problemas com que este último se vai deparando. No entanto, ocorreram alguns momentos de tensão pessoal, entre o presidente da Câmara e o diretor do Agrupamento, explicáveis pela necessidade de afirmação política, compreensíveis e próprios entre dois opositores políticos que disputam uma eleição autárquica. Pela ponderação redobrada com que reconhecem tomar decisões, esta disputa condiciona a gestão por parte destes dois líderes.

Assim, podemos afirmar que a intervenção da autarquia na educação revela, com frequência, dificuldades de organização e articulação, fruto de uma parceria que é trabalhosa, conflitual, mas igualmente enriquecedora e conferente de maior abrangência social dos objetivos.

Ficamos com a consciência de que no domínio da descentralização educativa e da mais recente opção pela municipalização muito trabalho de investigação fica por fazer. Numa perspetiva mais ambiciosa, seria interessante analisar/confrontar a coabitação de diversas perspetivas/programas de territorialização, como 
sejam, as escolas Territórios Educativos de Intervenção Prioritária, as escolas com contratos autonomia e os municípios com contratos piloto no âmbito do Programa "Aproximar Portugal".

\section{Sobre los autores}

Maria João de Carvalho doutorada em Educação/Organização e Administração Escolares. Professora auxiliar, Universidade de Trás-os-Montes e Alto Douro. Investigadora Integrada do Centro de Investigação e Intervenção Educativas-Universidade do Porto, Portugal. Diretora do Mestrado em Ciências da Educação-area de especialização em Administração Educacional. Avaliadora Externa de Escolas.

Armando Felizardo mestre em Ciências da Educação/Organização e Administração Educacional; Doutorando em Ciências da Educação da UTAD.

\section{Referências}

Baixinho, A. F. (2011). Educação e autarquias. Lógicas de acção do poder autárquico face ao poder central e aos micro-poderes locais. Revista Lusófona de Educação, 18, 81-95. Disponível em: http://revistas.ulu sofona.pt/index.php/rleducacao/issue/view/201

Baptista, S. (2014). Descentralização educativa e autonomia das escolas: para uma análise da situação de Portugal numa perspetiva comparada. Tese especialmente elaborada para obtenção do grau de Doutor em Sociologia. Instituto Universitário de Lisboa, Lisboa, dezembro 2014. Disponível em: https://repositorio.iscte-iul.pt/bitstre am/10071/9492/1/Tese_final_4.15.pdf

Fernandes, A. S. (1995). Educação e poder local. In Educação, comunidade e poder local: Actas do Seminário realizado em 6 e 7 de Dezembro de 1994, 45-63. Lisboa: Conselho Nacional de Educação. Disponível em: http://www.cnedu.pt/content/edicoes/seminarios_e_coloquios/ educacao-poder-local.pdf

Fernandes, A. S. (1996). Os municípios portugueses e a educação. As normas e as práticas. In J. Barroso \& J. Pinhal (orgs.). Administração da educação - Os caminhos da descentralização, 113-124. Lisboa: Edições Colibri.

Fernandes, A. S. (2004). Município, cidade e territorialização educativa. In J. A. Costa, A. Neto-Mendes \& A. Ventura (orgs.). Políticas e gestão local da escola: Actas do III Simpósio sobre organização e gestão escolar, 35-43. Aveiro: Universidade de Aveiro.

Fernandes, A. S. (2005). Descentralização, desconcentração e autonomia dos sistemas educativos: uma panorâmica europeia. In J. Formosinho, A. S. Fernandes, J. Machado \& F. I. Ferreira. Administração da Educação. Lógicas burocráticas e Lógicas de Mediação, 53-89. Porto: Edições Asa.

Fernandes, A. S. (2014). Contextos da intervenção educativa local e a experiência dos municípios portugueses. In J. Machado, J. M. Alves, A. S. Fernandes, J. Formosinho \& I. Vieiras. Municípios, educação e desenvolvimento local. Projetos educativos municipais, 35-61. Vila Nova de Gaia: Fundação Manuel Leão.

Fortin, M.-F.; Côté, J. \& Filion, F. (2009). Fundamentos e etapas do processo de investigação. Loures: Lusodidacta.

Laperrière, A. (1997). La théorisation ancrée (grounded theory): démarche analytique et comparaison avec d'autres approches apparentées. In J. Poupart, J.-P. Deslauriers, L. H. Groulx, A. Laperrière, R. Mayer \& 
A. P. Pires. La recherche qualitative: enjeux épistémologiques et méthodologiques, 309-340. Montréal, Canada: Gaëtan Morin Éditeur.

Neto-Mendes, A. (2007). A participação dos Municípios portugueses na Educação e a reforma do Estado - elementos para uma reflexão. Actas do V Congresso Luso-Brasileiro de Política e Administração da Educação - Por uma Escola de Qualidade para Todos. Porto Alegre, Brasil: Associação Nacional de Política e Administração da Educação, ANPAE (cd-rom).

Nóvoa, A. (2005). Evidentemente, histórias da educação. Porto: Edições ASA.

Pereira, D. (2010). Racionalidades e Práticas de Gestão do Pessoal Administrativo num Agrupamento de Escolas. Braga: Instituto de Educação e Psicologia da Universidade do Minho (dissertação de mestrado não publicada).

Pinhal, J. (2004). Os municípios e a provisão pública de educação. In J. A. Costa, A. Neto-Mendes \& A. Ventura (orgs.). Políticas e gestão local da escola: Actas do III Simpósio sobre organização e gestão escolar, 45-60. Aveiro: Universidade de Aveiro.

Pinhal, J. (2006). A intervenção do município na regulação local da escola. In J. Barroso (org.). A regulação das políticas públicas de educação: espaços, dinâmicas e actores, 99-128. Lisboa: Educa/Unidade de I\&D de Ciências da Educação.

Pinhal, J. (2011). A construção do sistema educativo local em Portugal: uma história recente. Cadernos de Pesquisa: Pensamento Educacional, 6 (12), 13-27. Disponível em: https://seer.utp.br/index.php/a/ article/view/425

Pinhal, J. (2013). Os municípios e a oferta educativa. In A. Adão \& J. MagaIhães (orgs.). História dos municípios na educação e na cultura: incertezas de ontem, desafios de hoje, 131-147. Instituto de Educação da Universidade de Lisboa. [e-book disponível em: www.ie.ul.pt]

Portugal (4 de Abril de 1976). Constituição da República Portuguesa. Diário da República, 86/1976, Série I de 1976-04-10. Disponível em: https:// dre.pt/legislacao-consolidada/-/lc/34520775/view

Portugal (1984). Decreto-Lei n. ${ }^{\circ} 77 / 84$, de 8 de março, estabelece o regime da delimitação e da coordenação das atuações da administração central e local em matéria de investimentos públicos. Diário da República, 57/1984, Série I de 1984-03-08. Disponível em: https://dre. tretas.org/dre/277/decreto-lei-77-84-de-8-de-marco

Portugal (1998). Decreto-Lei n. ${ }^{0} 115-A / 98$, de 4 de Maio, regime de autonomia, administração e gestão dos estabelecimentos da educação pré-escolar e dos ensinos básico e secundário. Diário da República, 102/1998, 1 Suplemento, Série I-A de 1998-05-04. Disponível em: https://dre.pt/web/guest/pesquisa/-/search/155636/details/maximized

Portugal (2003). Decreto-Lei n. ${ }^{\circ} 7 / 2003$, de 15 de Janeiro, regulamenta os conselhos municipais de educação e aprova o processo de elaboração de carta educativa, transferindo competências para as autarquias locais. Diário da República, 12/2003, Série I-A de 2003-01-15. Disponível em: https://dre.pt/pesquisa/-/search/176533/details/maximized

Portugal (2008). Decreto-Lei n. ${ }^{0}$ 144/2008, de 28 de Julho, quadro de transferência de competências para os municípios em matéria de educação. Diário da República, 144/2008, Série I de 2008-07-28. Disponível em: https://dre.pt/web/guest/pesquisa/-/search/454796/ details/maximized?p_p_auth $=$ WFqxhyp3

Portugal (2015). Decreto-Lei n. ${ }^{\circ}$ 30/2015, de 12 de fevereiro, estabelece o regime de delegação de competências nos municípios e entidades intermunicipais no domínio de funções sociais. Diário da República, 
30/2015, Série I de 2015-02-12. Disponível em: https://dre.pt/home/-/ dre/66487456/details/maximized?p_auth=CBzGbHK9

Portugal (1979). Lei n. ${ }^{\circ} 1 / 79$, de 2 de Janeiro, Lei das finanças locais. Diário da República, 1/1979, Série I de 1979-01-02. Disponível em: https:// dre.tretas.org/dre/114943/lei-1-79-de-2-de-janeiro

Portugal (1986). Lei n. ${ }^{\circ} 46 / 86$, de 14 de outubro, Lei de Bases do Sistema Educativo. Diário da República, 237/1986, Série I de 1986-10-14. Disponível em: https://dre.pt/web/guest/pesquisa/-/search/222418/ details/normal?p_p_auth $=$ D6880vBC

Portugal (1999). Lei n. ${ }^{\circ}$ 159/99, de 14 de Setembro, estabelece o quadro de transferência de atribuições e competências para as Autarquias Locais. Diário da República, 215/1999, Série I-A de 1999-09-14. Disponível em: https://dre.pt/pesquisa/-/search/570562/details/maximized

uivy, R. \& Campenhoudt, L. van (1992). Manual de investigação em ciências sociais. Lisboa: Gradiva.

Seabra, T.; Carmo R.; Baptista, I. \& Fontes, A. (2012). Avaliação da descentralização de competências de educação para os municípios. Lisboa: Ministério da Educação e Ciência. Disponível em: http://www.gepe. min-edu.pt/np4/\%7B\$clientServletPath\%7D/?newsld=268\&fileNa me=Relat_rio_final_Avalia_o_da_descentrali.pdf

Souza, D. \& Faria, L. (2004). Reforma do Estado, descentralização e municipalização do ensino no Brasil: a gestão política dos sistemas públicos de ensino Pós-LDB. 9.394/96. Ensaio, Avaliação, Políticas Públicas, 12 (45), 925-944. Disponível em: http://www.scielo.br/pdf/ensaio/ v12n45/v12n45a02.pdf

Tuckman, B. W. (2000). Manual de Investigação em Educação. Lisboa: Fundação Calouste Gulbenkian. 